\section{Emergency department utilization and risk factors for mortality in older patients: an analysis of Korean National Emergency Department Information System data}

\author{
Soyoon Kim ${ }^{1}$, Hyunggoo Kang ${ }^{1 *}$, Yongil Cho ${ }^{1 *}$, Heekyung Lee', \\ Sung Woo Lee ${ }^{2}$, Jinwoo Jeong ${ }^{3}$, Won Young Kim', Su Jin Kim², \\ Kap Su Han² \\ ${ }^{1}$ Department of Emergency Medicine, Hanyang University College of Medicine, Seoul, Korea \\ ${ }^{2}$ Department of Emergency Medicine, Korea University College of Medicine, Seoul, Korea \\ ${ }^{3}$ Department of Emergency Medicine, Dong-A University College of Medicine, Busan, Korea \\ ${ }^{4}$ Department of Emergency Medicine, Asan Medical Center, University of Ulsan College of Medicine, Seoul, \\ Korea
}

Objective With trends in population aging an increasing number of older patients are visiting the emergency department (ED). This study aimed to identify the characteristics of ED utilization and risk factors for in-hospital mortality in older patients who visited EDs.

Methods This nationwide observational study used National Emergency Department Information System data collected during a 2-year period from January 2016 to December 2017. The characteristics of older patients aged 70 years or older were compared with those of younger patients aged 20 to 69 years. Risk factors associated with in-hospital mortality were analyzed by multivariable logistic regression.

Results A total of 6,596,423 younger patients and 1,737,799 older patients were included. In the medical and nonmedical older patient groups, significantly higher proportions of patients were transferred from another hospital, utilized emergency medical services, had Korean Triage and Acuity Scale scores of 1 and 2, required hospitalization, and required intensive care unit admission in the older patient group than in the younger patient group. ED and post-hospitalization mortality rates increased with age; in particular, older medical patients aged 90 or older had an in-hospital mortality rate of 9\%. Older age, male sex, transfer from another hospital, emergency medical service utilization, a high Korean Triage and Acuity Scale score, systolic blood pressure $<100 \mathrm{mmHg}$, respiratory rate $>20 / \mathrm{min}$, heart rate $>100 / \mathrm{min}$, body temperature $<36^{\circ} \mathrm{C}$, and altered mental status were associated with in-hospital mortality.

Conclusion Development of appropriate decision-making algorithms and treatment protocols for high risk older patients visiting the ED might facilitate appropriate allocation of medical resources to optimize outcomes.

Keywords Aged; Emergency service, hospital; Mortality; Risk factors
elSSN: 2383-4625

Received: 12 August 2020

Revised: 1 November 2020

Accepted: 20 November 2020

Correspondence to: Hyunggoo Kang Department of Emergency Medicine, Hanyang University College of Medicine, 222-1 Wangsimni-ro, Seongdong-gu, Seoul 04763, Korea E-mail: emer0905@hanyang.ac.kr ORCID

https://orcid.org/0000-0002-9522-2532

Yongil Cho

Department of Emergency Medicine, Hanyang University College of Medicine, 222-1 Wangsimni-ro, Seongdong-gu, Seoul 04763, Korea E-mail: joeguy@hanyang.ac.kr ORCID https://orcid.org/0000-0001-5027-6345

*These two authors contributed equally to this work.

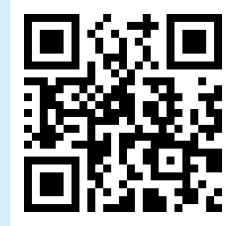

How to cite this article:

Kim S, Kang H, Cho Y, Lee H, Lee SW, Jeong J, Kim WY, Kim SJ, Han KS. Emergency department utilization and risk factors for mortality in older patients: an analysis of Korean National Emergency Department Information System data. Clin Exp Emerg Med 2021;8(2):128-136. https://doi. org/10.15441/ceem.20.098

This is an Open Access article distributed under the terms of the Creative Commons Attribution Non-Commercial License (https:// creativecommons.org/licenses/by-nc/4.0/). 


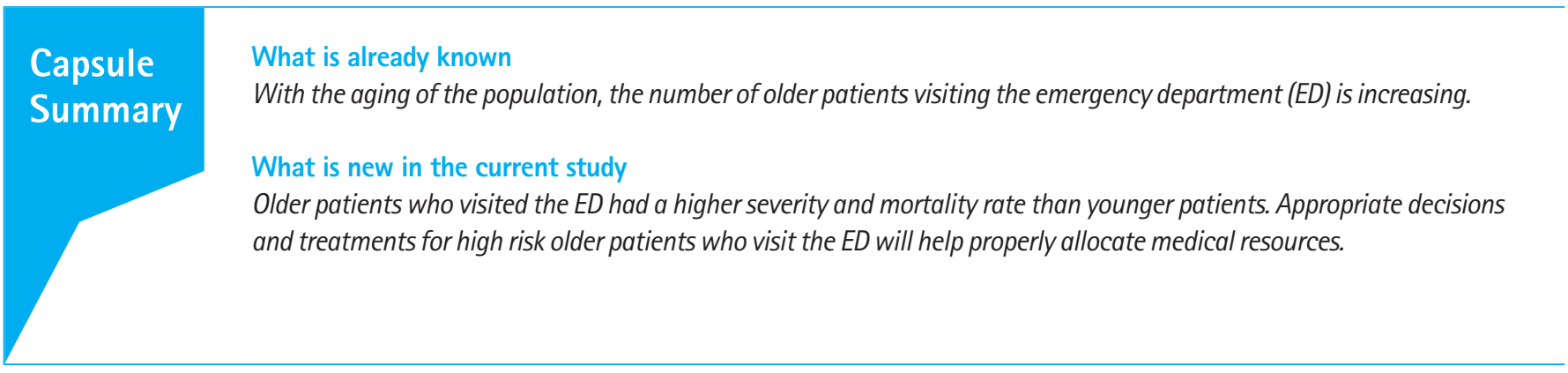

\section{INTRODUCTION}

The South Korean population is rapidly aging due to multiple factors, such as a higher life expectancy and decreased fertility rate. According to the Korean National Statistical Office, people aged 65 years or older constituted $14.4 \%$ of the total population of South Korea as of August 2018.' By 2026, South Korea is expected to become a superaged society, with 12 million people aged 65 years and older, accounting for more than $20 \%$ of the total population. $^{2}$

The number of older patients who visit the emergency department (ED) is increasing, with a resultant increase in medical expenses. ${ }^{3-7}$ In addition, older patients in long-term care facilities and nursing homes visit EDs for evaluation and care when their clinical condition worsens. ${ }^{8,9}$ Older patients have prolonged lengths of stay in the ED because of diagnostic difficulties as their symptoms are ambiguous and test results are often atypical. Hospitalization and mortality rates are higher in older patients than in younger patients who visit the ED.,10,11

Despite these circumstances, there are few nationwide studies on the characteristics of older patients who visit EDs in Korea. It is necessary to identify the disease severity, hospitalization rate, and mortality rate of older patients visiting EDs at the nationwide scale. In addition, identifying factors associated with in-hospital mortality that could be detected in the ED could help clinicians to focus on high risk older patients. This study was conducted to identify the characteristics of ED utilization and risk factors for mortality in older patients using a large nationally representative population.

\section{METHODS}

\section{Data source and setting}

This nationwide cross-sectional observational study was conducted using information that was obtained from the National Emergency Department Information System (NEDIS) database, which is managed by the Ministry of Health and Welfare and comprises nationwide data that include information on patients who visit EDs in Korea. We used NEDIS data collected during a 2-year period from January 2016 to December 2017. NEDIS includes patient demographics and clinical information, including age, sex, visit route, visit transportation, the Korean Triage and Acuity Scale (KTAS) score, vital signs, discharge outcomes, and diagnosis in the ED. The KTAS score is divided into five levels from 1 to 5 , with a lower score indicating higher clinical severity: Score 1 necessitates top priority for care and indicates a life-threatening condition, such as cardiac arrest, severe respiratory failure, and loss of consciousness, that requires immediate treatment; Score 2 indicates a potentially life-threatening condition, such as myocardial infarction, cerebral hemorrhage, and cerebral infarction, which requires rapid treatment; Score 3 indicates a condition that can eventually progress to cause serious complications; Score 4 represents a condition that requires treatment or reassessment within 1 to 2 hours and is associated with the patient's age, pain, and the likelihood of complications; and Score 5 indicates an urgent but nonemergent condition that is possibly caused by a chronic problem or a condition that is unlikely to worsen.

\section{Study population}

Adult patients (age $>20$ years) who visited EDs in Korea ( $\mathrm{n}=$ 13,731,531) between 2016 and 2017 were screened for inclusion in this study (Fig. 1). Among them, patients who visited EDs for non-care-related purposes, those who withdrew from ED treatment, or those with missing data on the purpose of the ED visit were excluded. A total of 8,334,222 patients visited EDs for medical or nonmedical purposes. Patients who were older than 70 years were defined as the older patient group, and patients aged between 20 and 69 years were defined as the younger patient group. These study groups were further divided into subgroups of medical patients and nonmedical patients; the nonmedical patient group included patients with trauma, injury, and poisoning. 
NEDIS 2016-2017

$13,731,531$ Number of emergency department visits ( $\geq 20$ years old)

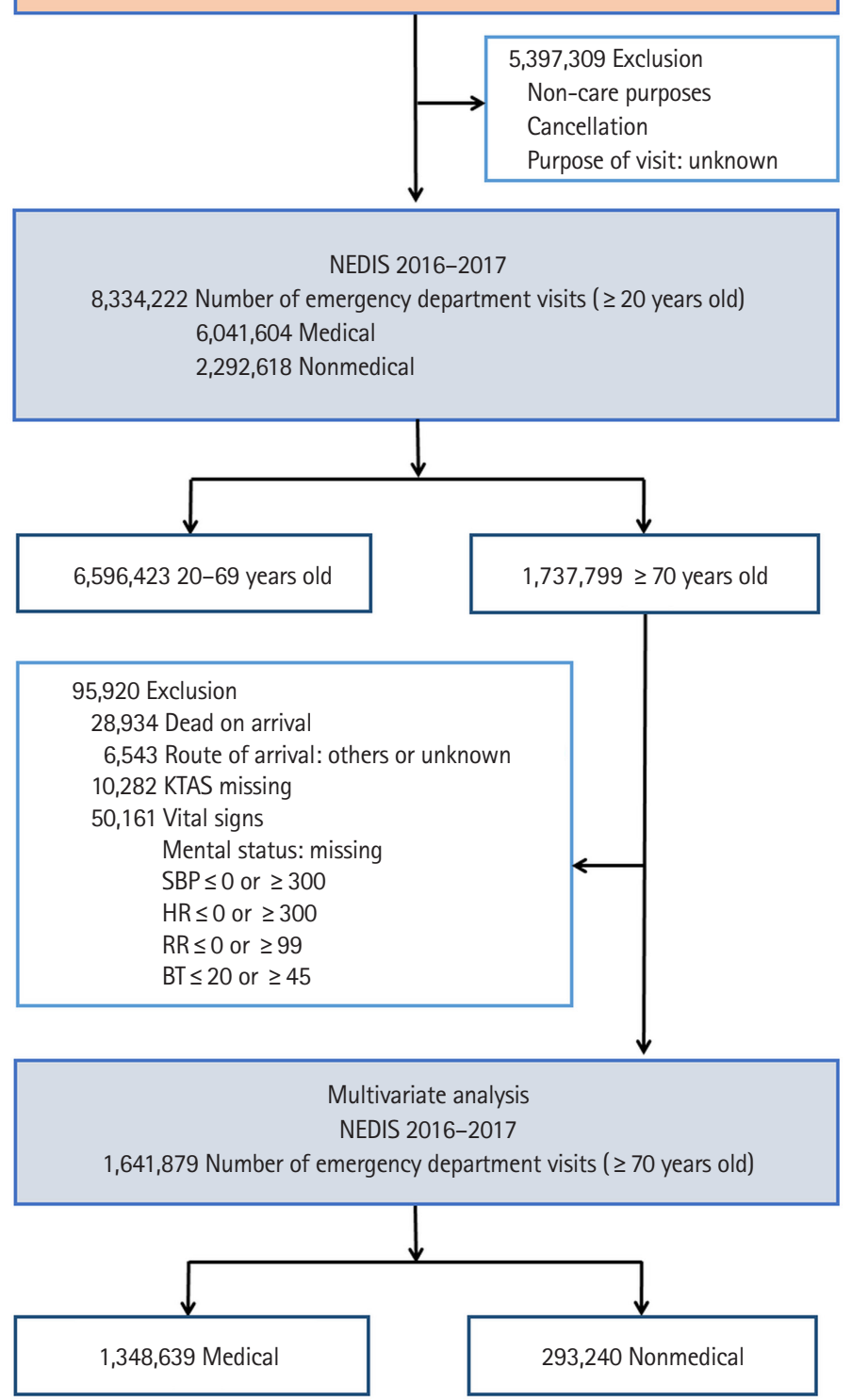

Fig. 1. Study flow diagram. NEDIS, National Emergency Department Information System; KTAS, Korean Triage and Acuity Scale; SBP, systolic blood pressure; $H R$, heart rate; $R R$, respiratory rate; $B T$, body temperature.

\section{Data collection}

The following information on patient characteristics and ED visits were extracted: age, sex, type of emergency medical center, KTAS score, emergency medical services (EMS) use, and transfer from another hospital. EMS refers to the public EMS system and does not include emergency services provided by hospitals or private ambulances. In addition, the following outcomes of patient visits were analyzed: hospitalization, discharge, transfer to another hospital, intensive care unit (ICU) admission, and mortality. For nonmedical patients, the mechanism of injury and intentionality were recorded.

After excluding patients who were dead on arrival, we classified patients who died in the ED or after hospitalization as those who died in the hospital. The age group, sex, route of arrival, EMS utilization, KTAS score, initial vital signs, and mental status were analyzed as potential risk factors for in-hospital mortality in older patients who visited the ED. Vital signs were categorized according to the following criteria, based on the results of previous studies: (1) systolic blood pressure (SBP, $<100$ vs. $\geq 100 \mathrm{mmHg}$ ); (2) respiratory rate $(\mathrm{RR},>20 / \mathrm{min}$ vs. $\leq 20 / \mathrm{min}) ;(3)$ heart rate $(H R$, 
$>100 / \mathrm{min}$ vs. $\leq 100 / \mathrm{min}$; and (4) body temperature $\left(\mathrm{BT}_{1}<36^{\circ} \mathrm{C}\right.$, $36^{\circ} \mathrm{C} \leq \mathrm{BT} \leq 38^{\circ} \mathrm{C}$, and $\left.\mathrm{BT}>38^{\circ} \mathrm{C}\right) . .^{12}$

\section{Statistical analysis}

Continuous variables are presented as the mean and standard deviation or median and interquartile range, as appropriate. The Anderson-Darling test was used to test the normality of the data. Categorical variables are presented as numbers and proportions $(\%)$. The chi-square test for categorical variables and the Wilcoxon rank sum test for continuous variables were used to compare the older and younger patient groups. For the analysis of risk factors for in-hospital mortality in the older patient group, adjusted odds ratios (aOR) and 95\% confidence intervals (Cl) were calculated using multivariable logistic regression. Variables that were expected to be related to in-hospital mortality were selected and included in a single model. Multivariate analysis was performed for medical and nonmedical patients. All statistical analyses were performed using R ver. 3.6.2 (R Foundation for Statistical Computing, Vienna, Austria).

\section{Ethics statement}

The study protocol was reviewed and approved by the institutional review board of Hanyang University Seoul Hospital (2020-04053), and the requirement for informed consent was waived because we used retrospective anonymized data.

\section{RESULTS}

\section{Characteristics of ED utilization in older patients} A total of 6,596,423 younger patients and 1,737,799 older patients were included to determine the baseline characteristics of patients who visited EDs (Fig. 1). Of the older patients, 1,641,879 were included in the multivariable analysis, and 95,920 patients were excluded. Of the $13,731,531$ adult patients who visited EDs in 2016 and 2017, 8,334,222 patients visited the ED for medical or nonmedical purposes (Fig. 1).

Older patients accounted for $23.6 \%(n=1,427,554)$ of the $6,041,604$ medical patients (Table 1). The median age of the older and younger patient groups was 78 and 46 years, respectively. In the older patient group, higher proportions of patients transferred from another hospital (21.2\%) and utilized EMS (29.0\%) than those in the younger patient group (9.3\% and $15.3 \%$, respectively). Similarly, the older patient group had a higher proportion of patients with severe disease (KTAS scores 1-2) than the younger patient group (19.1\% and 7.9\%, respectively). Older patients had 2, 3, and 5 times higher rates of hospitalization, ICU admission, and mortality, respectively, than the younger patients.

Older patients comprised $13.5 \%(n=310,245)$ of the $2,292,618$ nonmedical patients (Table 2). Similar to the medical patient group, higher proportions of patients in the older patient group transferred from another hospital (15.7\%) and utilized EMS (42.9\%) than in the younger group (5.9\% and $24.9 \%$, respectively). The commonest mechanism of trauma in the older patient group was

Table 1. Medical patients who visited emergency departments in 2016 to $2017(n=6,041,604)$

\begin{tabular}{|c|c|c|c|}
\hline & $20-69$ years old $(n=4,614,050)$ & $\geq 70$ years old $(n=1,427,554)$ & P-value \\
\hline Age (yr) & $46(34-57)$ & $78(74-83)$ & $<0.001$ \\
\hline Sex & & & $<0.001$ \\
\hline Male & $2,165,840(46.9)$ & $658,994(46.2)$ & \\
\hline Female & $2,448,210(53.1)$ & $768,560(53.8)$ & \\
\hline Type of emergency medical center & & & $<0.001$ \\
\hline Regional emergency medical center & $1,323,040(28.7)$ & $461,353(32.3)$ & \\
\hline Local emergency medical center & $3,094,948(67.1)$ & $927,143(64.9)$ & \\
\hline Local emergency medical facility & $196,062(4.2)$ & $39,058(2.7)$ & \\
\hline Transferred from another hospital & $430,153(9.3)$ & $302,441(21.2)$ & $<0.001$ \\
\hline EMS utilization & $705,817(15.3)$ & $413,452(29.0)$ & $<0.001$ \\
\hline KTAS score of $1-2$ & $365,393(7.9)$ & $272,232(19.1)$ & $<0.001$ \\
\hline \multicolumn{4}{|l|}{ ED disposition } \\
\hline Discharge & $3,540,269(76.7)$ & $686,413(48.1)$ & $<0.001$ \\
\hline Transfer out & $61,701(1.3)$ & $48,209(3.4)$ & $<0.001$ \\
\hline Hospitalization & $983,509(21.3)$ & $654,884(45.9)$ & $<0.001$ \\
\hline ICU admission & $147,647(3.2)$ & $146,528(10.3)$ & $<0.001$ \\
\hline Mortality & $53,298(1.2)$ & $93,456(6.5)$ & $<0.001$ \\
\hline
\end{tabular}

Values are presented as median (interquartile range) or number (\%).

EMS, emergency medical service; KTAS, Korean Triage and Acuity Scale; ED, emergency department; ICU, intensive care unit. 
Table 2. Nonmedical patients who visited emergency departments in 2016 to 2017 (n=2,292,618)

\begin{tabular}{|c|c|c|c|}
\hline & $20-69$ years old $(n=1,982,373)$ & $\geq 70$ years old $(n=310,245)$ & P-value \\
\hline Age (yr) & $44(32-55)$ & 77 (74-82) & $<0.001$ \\
\hline Sex & & & $<0.001$ \\
\hline Male & $1,181,340(59.6)$ & $130,401(42.0)$ & \\
\hline Female & $801,033(40.4)$ & $179,844(58.0)$ & \\
\hline Type of emergency medical center & & & $<0.001$ \\
\hline Regional emergency medical center & $528,504(26.7)$ & $87,501(28.2)$ & \\
\hline Local emergency medical center & $1,359,581(68.6)$ & $210,695(67.9)$ & \\
\hline Local emergency medical facility & $94,288(4.8)$ & $12,049(3.9)$ & \\
\hline Transferred from another hospital & $117,391(5.9)$ & $48,776(15.7)$ & $<0.001$ \\
\hline EMS utilization & $494,435(24.9)$ & $133,092(42.9)$ & $<0.001$ \\
\hline KTAS 1-2 & $101,722(5.1)$ & $24,401(7.9)$ & $<0.001$ \\
\hline \multicolumn{4}{|l|}{ Intentionality } \\
\hline Accidental & $1,719,412(86.7)$ & $284,906(91.8)$ & $<0.001$ \\
\hline Intentional/suicide & $44,667(2.3)$ & $5,816(1.9)$ & $<0.001$ \\
\hline Violence & $91,199(4.6)$ & $3,182(1.0)$ & $<0.001$ \\
\hline \multicolumn{4}{|l|}{ Mechanism } \\
\hline Traffic accident & $404,742(20.4)$ & $50,811(16.4)$ & $<0.001$ \\
\hline Fall & $92,633(4.7)$ & $24,537(7.9)$ & $<0.001$ \\
\hline Slipping & $285,028(14.4)$ & $127,478(41.1)$ & $<0.001$ \\
\hline Burn/fire & $56,816(2.9)$ & $2,883(0.9)$ & $<0.001$ \\
\hline Drowning/nearly drowning & $1,682(0.1)$ & $372(0.1)$ & $<0.001$ \\
\hline Poisoning & $55,874(2.8)$ & $9,814(3.2)$ & $<0.001$ \\
\hline Hanging/choking & $5,251(0.3)$ & $1,373(0.4)$ & $<0.001$ \\
\hline \multicolumn{4}{|l|}{ ED disposition } \\
\hline Discharge & $1,654,814(83.5)$ & $182,221(58.7)$ & $<0.001$ \\
\hline Transfer out & $36,105(1.8)$ & $12,651(4.1)$ & $<0.001$ \\
\hline Hospitalization & $273,545(13.8)$ & $111,304(35.9)$ & $<0.001$ \\
\hline ICU admission & $41,094(2.1)$ & $17,098(5.5)$ & $<0.001$ \\
\hline Mortality & $11,683(0.6)$ & $7,498(2.4)$ & $<0.001$ \\
\hline
\end{tabular}

Values are presented as median (interquartile range) or number (\%).

EMS, emergency medical service; KTAS, Korean Triage and Acuity Scale; ED, emergency department; ICU, intensive care unit.

slipping (41.1\%). Older patients had a 2.6 times higher rate of hospitalization and ICU admission than younger patients. Older patients had a 4 times higher mortality rate than younger patients $(2.4 \%$ vs. $0.6 \%)$.

\section{Risk factors for in-hospital mortality}

After excluding 46,748 dead on arrival patients, the in-hospital mortality rate of $8,287,474$ adult patients who visited EDs was stratified by age group (Fig. 2). In-hospital mortality increased with age, with a higher rate of increase in medical patients than in nonmedical patients. The proportions of medical patients who died in the ED or after hospitalization were approximately 5\% to $7 \%$ in patients aged 80 to 89 years and $9 \%$ in patients older than 90 years.

Among the older patients who visited EDs, 1,348,639 medical patients and 293,240 nonmedical patients were included in the multivariable analysis of risk factors for in-hospital mortality (Fig.

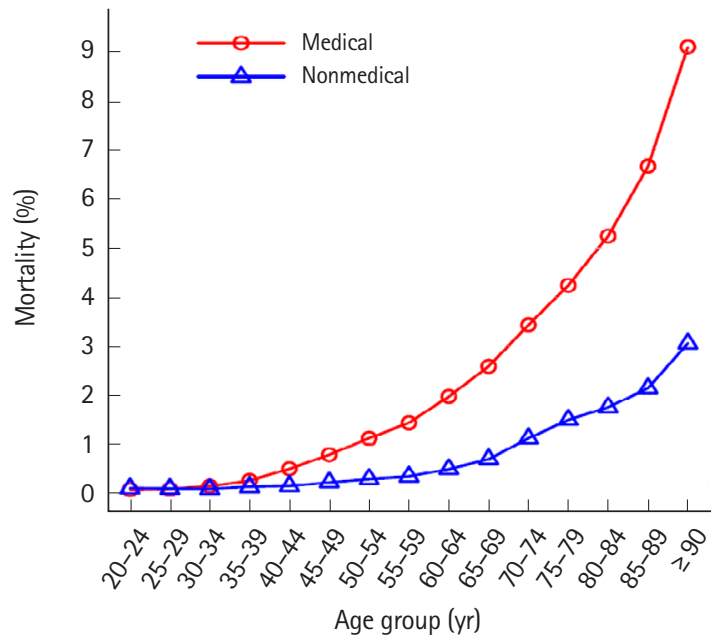

Fig. 2. In-hospital mortality rates by age group in medical and nonmedical patients who visited the emergency departments. 
1). Table 3 shows the results of the multivariable analysis that identified risk factors associated with in-hospital mortality in older medical patients. The risk of in-hospital mortality tended to increase with age and was 2.07 times higher in patients aged 90 years or older than in patients aged 70 to 74 years. The risk of inhospital mortality was higher in males $(\mathrm{aOR}, 1.45 ; 95 \% \mathrm{Cl}, 1.42-$ 1.47), in patients transferred from another hospital (aOR, 2.19; $95 \% \mathrm{Cl}, 2.14-2.23)$, and in patients with EMS utilization (aOR, $1.52 ; 95 \% \mathrm{Cl}, 1.48-1.55)$. Lower KTAS scores were associated with

Table 3. Multivariable logistic regression analysis of risk factors associated with in-hospital mortality in older medical patients (age $\geq 70$, $n=1,348,639)$

\begin{tabular}{|c|c|c|c|}
\hline & Adjusted OR & $95 \% \mathrm{Cl}$ & P-value \\
\hline \multicolumn{4}{|l|}{ Age (yr) } \\
\hline 70-74 (reference) & 1 & & \\
\hline $75-79$ & 1.15 & $1.12-1.17$ & $<0.001$ \\
\hline $80-84$ & 1.36 & $1.32-1.39$ & $<0.001$ \\
\hline $85-89$ & 1.62 & $1.57-1.66$ & $<0.001$ \\
\hline$\geq 90$ & 2.07 & $1.99-2.14$ & $<0.001$ \\
\hline \multicolumn{4}{|l|}{ Sex } \\
\hline Female (reference) & 1 & & \\
\hline Male & 1.45 & $1.42-1.47$ & $<0.001$ \\
\hline \multicolumn{4}{|l|}{ Route of arrival } \\
\hline Direct (reference) & 1 & & \\
\hline Transferred from another hospital & 2.19 & $2.14-2.23$ & $<0.001$ \\
\hline Transferred from OPD & 1.31 & $1.25-1.38$ & $<0.001$ \\
\hline \multicolumn{4}{|l|}{ EMS utilization } \\
\hline No (reference) & 1 & & \\
\hline Yes & 1.52 & $1.48-1.55$ & $<0.001$ \\
\hline \multicolumn{4}{|l|}{ KTAS score } \\
\hline 5 (reference) & 1 & & \\
\hline 4 & 1.12 & $1.05-1.19$ & $<0.001$ \\
\hline 3 & 1.80 & $1.70-1.90$ & $<0.001$ \\
\hline 2 & 2.63 & $2.48-2.80$ & $<0.001$ \\
\hline 1 & 3.71 & $3.47-3.97$ & $<0.001$ \\
\hline \multicolumn{4}{|l|}{ Initial vital signs } \\
\hline $\begin{array}{l}\text { SBP }<100 \mathrm{mmHg} \text { (reference: SBP } \\
\quad \geq 100 \mathrm{mmHg} \text { ) }\end{array}$ & 2.63 & $2.57-2.68$ & $<0.001$ \\
\hline $\mathrm{RR}>$ 20/min (reference: $\mathrm{RR} \leq 20 / \mathrm{min}$ ) & 1.89 & $1.85-1.93$ & $<0.001$ \\
\hline$H R>100 /$ min (reference: $H R \leq 100 / \mathrm{min}$ ) & 2.08 & $2.04-2.12$ & $<0.001$ \\
\hline \multicolumn{4}{|l|}{ BT } \\
\hline$<36^{\circ} \mathrm{C}$ (reference: $36^{\circ} \mathrm{C} \leq \mathrm{BT} \leq 38^{\circ} \mathrm{C}$ ) & 1.53 & $1.48-1.59$ & $<0.001$ \\
\hline$>38^{\circ} \mathrm{C}$ (reference: $36^{\circ} \mathrm{C} \leq \mathrm{BT} \leq 38^{\circ} \mathrm{C}$ ) & 0.79 & $0.77-0.82$ & $<0.001$ \\
\hline \multicolumn{4}{|l|}{ Mental status } \\
\hline Alert (reference) & 1 & & \\
\hline Verbally responsive & 2.05 & $2.00-2.11$ & $<0.001$ \\
\hline Painfully responsive & 2.74 & $2.66-2.82$ & $<0.001$ \\
\hline Unresponsive & 4.97 & $4.67-5.29$ & $<0.001$ \\
\hline
\end{tabular}

$\mathrm{OR}$, odds ratio; $\mathrm{Cl}$, confidence interval; $\mathrm{OPD}$, outpatient department; EMS, emergency medical services; KTAS, Korean Triage and Acuity Scale; SBP, systolic blood pressure; $R R$, respiratory rate; $H R$, heart rate; $B T$, body temperature. an increased risk of in-hospital mortality; a patient with KTAS score 1 had a 3.71 times higher risk of in-hospital mortality than a patient with KTAS Score 5. Among the initial vital signs, SBP $<100$ $\mathrm{mmHg}(\mathrm{aOR}, 2.63 ; 95 \% \mathrm{Cl}, 2.57-2.68), \mathrm{RR}>20 / \mathrm{min}(\mathrm{aOR}, 1.89$; 95\% Cl, 1.85-1.93), HR > 100/min ( $\mathrm{aOR}, 2.08 ; 95 \% \mathrm{Cl}, 2.04-2.12)$, and $\mathrm{BT}<36^{\circ} \mathrm{C}(\mathrm{aOR}, 1.53 ; 95 \% \mathrm{Cl}, 1.48-1.59)$ were associated increased risks of in-hospital mortality. Patients with a $\mathrm{BT}>38^{\circ} \mathrm{C}$ had a $21 \%$ lower risk of in-hospital mortality $(\mathrm{aOR}, 0.79 ; 95 \% \mathrm{Cl}$ $0.77-0.82$ ) than those with a BT between $36^{\circ} \mathrm{C}$ and $38^{\circ} \mathrm{C}$. Patients

Table 4. Multivariable logistic regression analysis of in-hospital mortality in older nonmedical patients (age $\geq 70, n=293,240$ )

\begin{tabular}{|c|c|c|c|}
\hline & Adjusted OR & $95 \% \mathrm{Cl}$ & P-value \\
\hline \multicolumn{4}{|l|}{ Age (yr) } \\
\hline 70-74 (reference) & 1 & & \\
\hline $75-79$ & 1.36 & $1.24-1.49$ & $<0.001$ \\
\hline $80-84$ & 1.79 & $1.63-1.96$ & $<0.001$ \\
\hline $85-89$ & 2.43 & $2.18-2.70$ & $<0.001$ \\
\hline$\geq 90$ & 3.92 & $3.46-4.43$ & $<0.001$ \\
\hline \multicolumn{4}{|l|}{ Sex } \\
\hline Female (reference) & 1 & & \\
\hline Male & 1.71 & $1.60-1.83$ & $<0.001$ \\
\hline \multicolumn{4}{|l|}{ Route of arrival } \\
\hline Direct (reference) & 1 & & \\
\hline Transferred from another hospital & 2.79 & $2.53-3.08$ & $<0.001$ \\
\hline Transferred from OPD & 1.57 & $0.90-2.55$ & 0.087 \\
\hline \multicolumn{4}{|l|}{ EMS utilization } \\
\hline No (reference) & 1 & & \\
\hline Yes & 2.28 & $2.07-2.50$ & $<0.001$ \\
\hline \multicolumn{4}{|l|}{ KTAS score } \\
\hline 5 (reference) & 1 & & \\
\hline 4 & 1.51 & $1.23-1.89$ & $<0.001$ \\
\hline 3 & 2.78 & $2.26-3.45$ & $<0.001$ \\
\hline 2 & 7.14 & $5.76-8.95$ & $<0.001$ \\
\hline 1 & 10.85 & $8.50-13.96$ & $<0.001$ \\
\hline \multicolumn{4}{|l|}{ Initial vital signs } \\
\hline $\begin{array}{l}\text { SBP }<100 \mathrm{mmHg} \text { (reference: SBP } \\
\quad \geq 100 \mathrm{mmHg})\end{array}$ & 2.41 & $2.18-2.66$ & $<0.001$ \\
\hline $\mathrm{RR}>20 / \mathrm{min}$ (reference: $\mathrm{RR} \leq 20 / \mathrm{min}$ ) & 1.46 & $1.34-1.59$ & $<0.001$ \\
\hline$H R>100 /$ min (reference: $H R \leq 100 / \mathrm{min})$ & 1.77 & $1,63-1.92$ & $<0.001$ \\
\hline \multicolumn{4}{|l|}{ BT } \\
\hline$<36^{\circ} \mathrm{C}$ (reference: $36^{\circ} \mathrm{C} \leq \mathrm{BT} \leq 38^{\circ} \mathrm{C}$ ) & 1.37 & $1.22-1.54$ & $<0.001$ \\
\hline$>38^{\circ} \mathrm{C}$ (reference: $36^{\circ} \mathrm{C} \leq \mathrm{BT} \leq 38^{\circ} \mathrm{C}$ ) & 0.88 & $0.70-1.11$ & 0.289 \\
\hline \multicolumn{4}{|l|}{ Mental status } \\
\hline Alert (reference) & 1 & & \\
\hline Verbally responsive & 2.90 & $2.61-3.22$ & $<0.001$ \\
\hline Painfully responsive & 5.32 & $4.77-5.93$ & $<0.001$ \\
\hline Unresponsive & 12.84 & $10.86-15.18$ & $<0.001$ \\
\hline
\end{tabular}

$\mathrm{OR}$, odds ratio; $\mathrm{Cl}$, confidence interval; $\mathrm{OPD}$, outpatient department; $\mathrm{EMS}$, emergency medical services; KTAS, Korean Triage and Acuity Scale; SBP, systolic blood pressure; $R R$, respiratory rate; $H R$, heart rate; $B T$, body temperature. 
with an unresponsive mental status had a fivefold higher risk of in-hospital mortality (aOR, 4.97; 95\% Cl, 4.67-5.29) than patients with an alert mental status.

Table 4 shows the results of the multivariable analysis of inhospital mortality in older nonmedical patients. Similarly as in older medical patients, in the older nonmedical patient group, patients aged 90 years or older (aOR, 3.92; 95\% Cl, 3.46-4.43), males (aOR, 1.71; 95\% Cl, 1.60-1.83), patients transferred from another hospital (aOR, 2.79; 95\% Cl, 2.53-3.08), and patients with EMS utilization $(\mathrm{aOR}, 2.28 ; 95 \% \mathrm{Cl}, 2.07-2.50)$ had higher risks of in-hospital mortality than each corresponding control group. Patients with KTAS Score 1 had a 10.85-fold higher risk of in-hospital mortality than patients with KTAS score 5. Moreover, $\mathrm{SBP}>100 \mathrm{mmHg}(\mathrm{aOR}, 2.41 ; 95 \% \mathrm{Cl}, 2.18-2.66), \mathrm{RR}>20 / \mathrm{min}$ (aOR, 1.46; 95\% Cl, 1.34-1.59), HR > 100/min (aOR, 1.77; 95\% $\mathrm{Cl}, 1.63-1.92)$, and $\mathrm{BT}<36^{\circ} \mathrm{C}(\mathrm{aOR}, 1.37 ; 95 \% \mathrm{Cl}, 1.22-1.54)$ were associated with increased risks of in-hospital mortality. However, the risk of in-hospital mortality did not significantly differ in patients with a $\mathrm{BT}>38^{\circ} \mathrm{C}$ and those with normal $\mathrm{BT}\left(36^{\circ} \mathrm{C}-38^{\circ} \mathrm{C}\right)$. Patients with an unresponsive mental status had a 13-fold higher risk of in-hospital mortality $(\mathrm{aOR}, 12.84 ; 95 \% \mathrm{Cl}, 10.86-15.18)$ than patients with an alert mental status.

\section{DISCUSSION}

This nationwide study confirmed that older patients who visited EDs had higher illness severity and required more medical resources than younger patients. In addition, this study identified the association between factors identifiable from the information that is obtained in the initial evaluation and the in-hospital mortality rate in older patients visiting EDs. Therefore, we confirmed that the initial evaluation through NEDIS and KTAS is useful for evaluating the illness severity of patients visiting EDs.

In many countries, the proportions of older patients who visit the ED are gradually increasing, and the burden on EDs is increasing. ${ }^{3-7}$ Accordingly, there is a need to provide improved and organized ED care for older patients. To this end, an in-depth analysis of older patients visiting the ED is required to develop appropriate management protocols. Studies on the characteristics and importance of older patients visiting EDs in the United States and the United Kingdom have been conducted previously ${ }^{3,4,13}$; however, nationwide research on the use of EDs by older patients in Korea is scarce. This study confirmed that participants in the older patient group had a higher severity, hospitalization rate, and mortality rate than those in the younger patient group. Accordingly, the consumption of medical resources by the older patient group is considered to be significantly greater than that by the younger patient group. ${ }^{14}$
To identify older patients with a high risk of mortality at the time of the ED visit, we investigated the associated risk factors. The mortality rate of older patients was associated with age, male sex, the KTAS score, and the initial vital signs. Based on the results of this study, when an older patient visits an ED, rapid decision-making and appropriate initial treatment are needed to optimize outcomes.

Older age is an important risk factor for in-hospital mortality in patients. The in-hospital mortality rate among patients admitted to the ED was 3\% in the United States; however, few studies have analyzed in-hospital mortality by age group. ${ }^{15}$ In this study, the in-hospital mortality rate of older patients aged 70 years or older was $6.5 \%$ and $2.4 \%$ in the medical and nonmedical patient groups, respectively, and the risk of mortality increased rapidly with age. Male patients had a higher mortality rate than female patients. However, it is unclear whether the difference in the risk of in-hospital mortality is directly associated with sex differences or is attributable to other unmeasured covariates, such as comorbidities; therefore, further studies are needed to ascertain the factors associated with the abovementioned differences in mortality rates between the sexes.

The mortality rate of transferred patients was more than twice that of those who directly visited the hospital. This is probably because patients with severe diseases are frequently transferred to higher-level hospitals. There is a need to establish a medical system that coordinates the transfer of patients from long-term care facilities to the EDs of higher-level hospitals.

Older patients used EMS to visit EDs more often than did the younger patients. ${ }^{16,17}$ In this study, the proportion of older patients who utilized EMS was twice that of younger patients. Patients using EMS usually have severe disease. ${ }^{18}$ In this study, older patients using EMS had a higher risk of mortality than younger patients, and the EMS and EDs need to be prepared for the increase in the population of older patients. Furthermore, the mortality rate increased as the KTAS score decreased, which suggests that the KTAS score is correlated with disease severity. The KTAS is a highly reliable 5-level triage tool; in particular, the initial original KTAS score is associated with ED disposition. ${ }^{19,20}$

The initial vital signs of patients who visited the ED were independent predictors of in-hospital mortality. ${ }^{21}$ Initial vital signs are objective indicators that can be used for the simple and rapid evaluation of patients at risk immediately after presentation at the ED. Low SBP, rapid RR, rapid HR, and a Glasgow Coma Scale (GCS) score $<15$ have been associated with an increased risk of in-hospital mortality, despite minor differences in the results of studies. ${ }^{22,23}$ We identified the associations of early vital signs in older patients in the ED with the risk of in-hospital mortality. Older 
medical patients with a $\mathrm{BT}<36^{\circ} \mathrm{C}$ had a higher mortality rate than patients with a normal $\mathrm{BT}\left(36^{\circ} \mathrm{C} \leq \mathrm{BT} \leq 38^{\circ} \mathrm{C}\right)$. A BT $>38^{\circ} \mathrm{C}$ was associated with low mortality in older medical patients. SchellChaple et al. ${ }^{24}$ reported that the mortality risk decreased with increased BT in patients who had acute respiratory distress syndrome. Another study among patients with sepsis showed that febrile patients had a lower mortality risk, whereas hypothermic patients had higher mortality than patients with normal $\mathrm{BT}^{25}$ The cause for this association is controversial. According to one hypothesis, in the case of septic patients, fever occurs due to the secretion of small amounts of endotoxin, which gradually increases until the body transitions from a febrile state to one with normal BT and eventually to hypothermia. In trauma patients, hypothermia adversely affects various organs, causes coagulopathy, and increases mortality. ${ }^{26}$ In this study, hypothermia in nonmedical older patients increased the in-hospital mortality risk. However, the mortality risk did not differ significantly between patients with a BT $>38^{\circ} \mathrm{C}$ and those with normal BT.

Thus, it is important to allocate appropriate medical resources to older patients in EDs. A national evaluation program for EDs needs to be established to reduce the ED length of stay and inhospital mortality in older patients. ${ }^{27}$ In addition, the establishment of specialized centers for older emergency patients, similar to the pediatric EDs, should be considered.

This study has several limitations. First, this study analyzed data for a study period of only 2 years and does not reflect long-term trends. However, this study reflects the recent situation in actual EDs in Korea. Thus, these results may be helpful for establishing medical policies and clinical treatment protocols for older patients. Second, this study included only the NEDIS variables that were identified at the time of the ED visit and did not consider all clinical data, such as laboratory or radiologic findings, or comorbidities associated with in-hospital mortality. Therefore, future studies that include additional medical information besides the NEDIS data used in this study are necessary. The mortality-related factors included initial vital signs, mental status, the KTAS score, and EMS use, and these factors may be sufficient to predict the inhospital mortality risk during the early stages of the ED visit.

Older patients who visited the ED had a higher severity and mortality rate than younger patients. In particular, the mortality rate increased with age. Factors associated with in-hospital mortality in the ED or after hospitalization included male sex, transfer from another hospital, EMS utilization, a lower KTAS score, initial vital signs (low SBP, rapid RR, rapid $H R$, and low $B T$ ), and decreased mental status. Based on the understanding of the characteristics of older patients, it is necessary to consider measures to improve ED care for older patients.

\section{CONFLICT OF INTEREST}

No potential conflict of interest relevant to this article was reported.

\section{ACKNOWLEDGMENTS}

Kang H, Lee SW, Jeong J, Kim WY, Kim SJ, and Han KS received support for this study as part of the task force from the Korean Society of Emergency Medicine.

\section{REFERENCES}

1. Statistics Korea. Population statistics based on resident registration by age [Internet]. Daejeon: Korean Statistical Information Service; 2021 [cited 2020 Jan 6]. Available from: https:// kosis.kr/statHtml/statHtml.do?orgld = 101\&ttblld = DT_1B0400 6Ctconn_path $=12$.

2. Vital Statistics Division Statistics Korea, Shin HY, Lee JY, et al. Cause-of-death statistics in 2016 in the Republic of Korea. J Korean Med Assoc 2018;61:573-84.

3. Albert M, McCaig LF, Ashman JJ. Emergency department visits by persons aged 65 and over: United States, 2009-2010. NCHS Data Brief 2013:1-8.

4. Roberts DC, McKay MP, Shaffer A. Increasing rates of emergency department visits for elderly patients in the United States, 1993 to 2003. Ann Emerg Med 2008;51:769-74.

5. Kahn JH, Magauran BG Jr, Olshaker JS, Shankar KN. Current trends in geriatric emergency medicine. Emerg Med Clin North Am 2016;34:435-52.

6. Wittenberg R, Sharpin L, McCormick B, Hurst J. Understanding emergency hospital admission of older people [Internet]. Oxford: Centre for Health Service Economics \& Organisation; 2014 [cited 2020 Jun 4]. Available from: https://www.chseo. org.uk/downloads/report6-emergencyadmissions.pdf.

7. Ukkonen $M$, Jamsen $E$, Zeitlin R, Pauniaho SL. Emergency department visits in older patients: a population-based survey. BMC Emerg Med 2019;19:20.

8. Choi GJ, Lee BC, Sun ML. Characteristics and illness behaviors of the elderly patients who visited emergency department by emergency medical senvices. Korean J Fam Pract 2012;2:241-9.

9. Carron PN, Mabire C, Yersin B, Bula C. Nursing home residents at the Emergency Department: a 6-year retrospective analysis in a Swiss academic hospital. Intern Emerg Med 2017;12:22937.

10. Grief CL. Patterns of ED use and perceptions of the elderly regarding their emergency care: a synthesis of recent research. 
J Emerg Nurs 2003;29:122-6.

11. Ham EM, Kim HB, Pyo CH, et al. Analysis of epidemiologic characteristics between patients visited from residential aged care facilities and elderly patients visited from home admitted to the emergency department with disease. J Korean Soc Emerg Med 2017;28:87-96.

12. Ng CJ, Liao PJ, Chang YC, Kuan JT, Chen JC, Hsu KH. Predictive factors for hospitalization of nonurgent patients in the emergency department. Medicine (Baltimore) 2016;95:e4053.

13. Garcia-Pena C, Perez-Zepeda MU, Robles-Jimenez LV, Sanchez-Garcia S, Ramirez-Aldana R, Tella-Vega P. Mortality and associated risk factors for older adults admitted to the emergency department: a hospital cohort. BMC Geriatr 2018;18:144.

14. Aminzadeh F, Dalziel WB. Older adults in the emergency department: a systematic review of patterns of use, adverse outcomes, and effectiveness of interventions. Ann Emerg Med 2002;39:238-47.

15. Kocher KE, Haggins AN, Sabbatini AK, Sauser K, Sharp AL. Emergency department hospitalization volume and mortality in the United States. Ann Emerg Med 2014;64:446-57.

16. Platts-Mills TF, Leacock B, Cabanas JG, Shofer FS, McLean SA. Emergency medical services use by the elderly: analysis of a statewide database. Prehosp Emerg Care 2010;14:329-33.

17. Shah MN, Bazarian JJ, Lerner EB, Fairbanks RJ, Barker WH, Auinger $\mathrm{P}$, et al. The epidemiology of emergency medical services use by older adults: an analysis of the National Hospital Ambulatory Medical Care Survey. Acad Emerg Med 2007;14: 441-7.

18. Squire BT, Tamayo A, Tamayo-Sarver JH. At-risk populations and the critically ill rely disproportionately on ambulance transport to emergency departments. Ann Emerg Med 2010;56: 341-7.

19. Ryu JH, Min MK, Lee DS, et al. Changes in relative importance of the 5-level triage system, Korean triage and acuity scale, for the disposition of emergency patients induced by forced reduction in its level number: a multi-center registry-based retrospective cohort study. J Korean Med Sci 2019;34:e114.

20. Park JB, Lee J, Kim YJ, Lee JH, Lim TH. Reliability of Korean triage and acuity scale: interrater agreement between two experienced nurses by real-time triage and analysis of influencing factors to disagreement of triage levels. J Korean Med Sci 2019;34:e189.

21. Merz TM, Etter $R$, Mende $L$, et al. Risk assessment in the first fifteen minutes: a prospective cohort study of a simple physiological scoring system in the emergency department. Crit Care 2011;15:R25.

22. Hong W, Earnest A, Sultana P, Koh Z, Shahidah N, Ong ME. How accurate are vital signs in predicting clinical outcomes in critically ill emergency department patients. Eur J Emerg Med 2013;20:27-32.

23. Barfod C, Lauritzen MM, Danker JK, et al. Abnormal vital signs are strong predictors for intensive care unit admission and inhospital mortality in adults triaged in the emergency department: a prospective cohort study. Scand J Trauma Resusc Emerg Med 2012;20:28.

24. Schell-Chaple HM, Puntillo KA, Matthay MA, Liu KD; National Heart, Lung, and Blood Institute Acute Respiratory Distress Syndrome Network. Body temperature and mortality in patients with acute respiratory distress syndrome. Am J Crit Care 2015;24:15-23.

25. Rumbus $Z$, Matics $R$, Hegyi $P$, et al. Fever is associated with reduced, hypothermia with increased mortality in septic patients: a meta-analysis of clinical trials. PLoS One 2017;12: e0170152.

26. Perlman R, Callum J, Laflamme $C$, et al. A recommended early goal-directed management guideline for the prevention of hypothermia-related transfusion, morbidity, and mortality in severely injured trauma patients. Crit Care 2016;20:107.

27. Han KS, Kim WY, Kim SJ, et al. Research for improvement of the national evaluation program for emergency medical center in Korea. J Korean Med Assoc 2020;63:227-34. 